\title{
Exploring explanations for the gender gap in study abroad: a case study of the Netherlands
}

\author{
Christof Van Mol $^{1}$ (iD
}

Accepted: 21 December 2020 / Published online: 11 January 2021

(c) The Author(s) 2021

\begin{abstract}
The overrepresentation of female students in study abroad programmes across the Western world represents one of the major gaps in scientific research on study abroad. In this paper, I explore possible theoretical and empirical explanations, drawing on Personal Investment Theory and investigating study abroad motivations and decisions of a nationally representative sample of higher education students in the Netherlands between 2006 and 2015. The analyses specifically focus on the role of parents, academic self-concept and perceived goals in female and male students decision-making process to participate in study abroad programmes. The results reveal that maternal educational attainment level potentially plays a crucial role in explaining the decision-making process of both male and female students, as well as in explaining the overrepresentation of female students. The findings indicate that female students whose mothers have a medium educational attainment level are more likely to study abroad for exploration motives, whereas female students with lower educated mothers are more motivated by professional development purposes. As such, the results suggest mothers might motivate their daughters to study abroad in order to achieve intergenerational social mobility. Together, the presented findings offer fresh theoretical and empirical explanations of the gender gap in study abroad. Furthermore, the generated insights open up new directions for future research, indicating particularly the potential of social reproduction theories for explaining the gender gap in study abroad.
\end{abstract}

Keywords International student mobility $\cdot$ Study abroad $\cdot$ Gender $\cdot$ Motivations $\cdot$ The Netherlands

\section{Introduction}

In Australia, Europe and the USA, female students are more likely to study abroad compared with male students (European Commission 2017; Hurst 2019; Institute of International Education 2017; Luo and Jamieson-Drake 2015). This gender gap is consistent across subject areas and countries (Böttcher et al. 2016; Redden 2008). Today, this unequal gender balance remains unexplained and represents one of the major empirical

Christof Van Mol

C.VanMol@tilburguniversity.edu

1 Department of Sociology, Tilburg University, Warandelaan 2, 5037 AB Tilburg, The Netherlands 
and theoretical gaps in research into study abroad (King and Raghuram 2013; Salisbury et al. 2010). In this paper, I aim to fill this gap, exploring how study abroad decisionmaking processes might differ among female and male higher education students in the Netherlands.

The analysis is based on the Dutch Student Monitor 2006-2015, which annually collects information among a representative sample of Dutch higher education students. My focus on gendered motivations to participate in study abroad allows us to make a unique contribution to the academic literature. After all, despite the consistently documented gender gap in study abroad, few scholars tried to explain the mechanisms behind it, and merely include gender as a control variable or ancillary influencing factor in their statistical models (Netz et al. 2021). In this exploratory attempt to explain the disproportionate participation of female students in study abroad programmes, I expect explanations might derive from motivational theories that explain differences in broader individual educational decision-making processes throughout students' higher education studies. It has been well established that women and men have different trajectories through higher education (e.g. Ackerman et al. 2013; Thiele et al. 2015). Consequently, I investigate whether the gender gap in study abroad relates to gender differences in the determinants of general academic decision-making processes.

\section{Background}

The literature on study abroad decision-making processes of higher education students paid-surprisingly-little attention to gender dynamics, despite the consistent overrepresentation of women in international exchange programmes. As Salisbury et al. (2010) already indicated a decade ago, virtually no studies exist that empirically investigate the substantial differences in participation rates of male and female students. Today, this still holds true. Altogether, the few available studieswhich are reviewed below-suggest particularly motivations to participate in study abroad are gendered. But why this is the case remains a black box. In this paper, I therefore start from a classical motivation theory, namely Personal Investment Theory (PIT), and apply this theory to the decision to study abroad.

\section{Personal investment theory and gendered educational choices}

In this paper, I start from the premise that academic motivation might play a key role in study abroad decisions, as academic motivations are one of the key determinants of students' efforts and educational choices (Litalien et al. 2017). In this respect, Personal Investment Theory is a useful theory, as it explains why students invest in particular activities during their educational trajectory (King et al. 2019). Although PIT has been used extensively in educational psychology and cross-cultural psychology (King et al. 2019), it has not yet been applied to the study abroad decision-making process of higher education students, and for certain components of the theory-such as perceived goals-only few studies analysed gender differences (Litalien et al. 2017). PIT proposes that three main components influence the choice of individuals to invest in particular activities, namely (1) facilitating conditions, (2) 
sense of self and (3) perceived goals. I elaborate on each of these three components in relation to the gender gap in study abroad below.

\section{Facilitating conditions: the role of social networks and broader contexts}

First, facilitating conditions refer to the social and contextual situation wherein an individual is situated, which 'makes certain options more available and salient in contrast to other less appealing alternatives' (King et al. 2019: 2). In PIT studies, facilitating conditions generally point-but are not limited to-the influence of parents, teachers, and peers as well as the school and broader socio-cultural context (King et al. 2019). Also, in research on study abroad, it has been well established that parents and peers as well as wider economic, educational and political contexts play a significant role in study abroad decisions (e.g. Beerkens et al. 2016; Brooks and Waters 2021; Luo and Jamieson-Drake 2015; Rodríguez González et al. 2011). With regard to the family background, there is abundant research indicating students from higher socio-economic backgrounds are more likely to participate in study abroad (Lörz et al. 2016; Netz et al. 2021). However, empirical research on how such contextual factors interact with gender is almost non-existent, exceptto my knowledge-for two studies conducted among samples of US liberal arts college students. The study of Salisbury et al. (2010) thereby suggested that higher levels of parental education positively influenced female students' study abroad aspirations, whereas this was not the case for male students. A more recent study by Hurst (2019: 1251) came to broadly similar findings: her results indicated that the overrepresentation of women in study abroad can be particularly attributed to an overrepresentation of 'elite women', which she suggests might be related to gendered social reproduction strategies. Salisbury et al. (2010), on their turn, suggested that gender differences in study abroad might be related to the different ways in which male and female students make educational decisions. From this perspective, relying on PIT is relevant, as the theory precisely explains such decisions.

\section{Sense of self}

Second, in PIT sense of self refers to 'the more or less organized collections of perceptions, beliefs, and feelings about who one is'. (King et al. 2019: 3). Academic self-concept, which points to one's perception of general educational ability or skills (Kadir and Yeung 2016), is thereby most used among PIT researchers, which is further split into positive and negative academic self-concept (King et al. 2019). Research thereby consistently indicates that academic self-concept is positively correlated with students' grades (e.g. Awad 2007; Cokley and Patel 2007; Isiksal 2010). To my knowledge, studies on study abroad decisions did not yet investigate the correlation with students' academic self-concept. However, as in PIT it is expected students' sense of self partly inform their decisions to invest in particular activities, I expect to find a positive correlation between students' academic self-concept and the decision to study abroad, both for male and female students. After all, no gender differences are reported regarding the relationship between students' sense of self and educational achievement (Cokley et al. 2015). As such, I do not expect academic sense of self to explain the gender gap in study abroad. 


\section{Perceived goals}

Third, perceived goals refer to 'reasons or purposes for engaging in a task' (King et al. 2019: 3). In PIT studies, researchers commonly focus on four types of goals: mastery goals (wanting to do well because of personal interests), performance goals (wanting to do well to outperform others), social goals (seeking to help others and enhance sense of belonging) and extrinsic goals (seeking social recognition and tangible rewards). The few existing studies that investigated gender differences in achievement goal orientations in educational settings revealed no clear pattern, pointing to the importance of moderators such as classroom context (Meece et al. 2006). However, as female students seem to be more likely to value the opinions of parents, friends and relatives regarding study abroad (e.g. Presley et al. 2010; Shirley 2006), I expect a significant correlation between social goals and study abroad decisions among female students.

\section{Gendered individual motivations to study abroad}

Personal Investment Theory provides a useful background for studying the correlation between students' the determinants of general academic motivation and study abroad decisions. However, I also aim to investigate whether individual motivations for studying abroad differ across male and female students. The handful of existing studies on the subject among American college students (Kim and Goldstein 2005; Presley et al. 2010; Tompkins et al. 2017) indicate female students are more likely to consider study abroad as a possibility to experience a new culture and personal development compared with male students. However, such findings were not reported in Shirley's (2006) cross-sectional study of 179 college students who participated in a study abroad programme in Fall 2003. Furthermore, Presley et al. (2010) indicated female students are more likely to fear a delay in their academic progress and are more concerned about costs factors compared with male students. Shirley (2006) comes to broadly similar findings regarding female students' concerns about costs, and also indicated having a job is a significant barrier to participation in international student exchanges.

In sum, in this paper I apply Personal Investment Theory to study abroad decisions and investigate individual study abroad motivations among Dutch higher education students with a gender lens.

\section{Methods}

\section{Data}

My analysis is based on the Dutch Student Monitor 2006-2015-except for 2010 as no data was available for that survey year-which is annually conducted in spring since 2001. The Dutch Student Monitor monitors key developments and provides insight into the socio-economic dimension of Dutch higher education. The Monitor relies on the procedure of stratified sampling, and post-stratification weights are applied to make the survey representative for the national student population. The mean response rate of the survey is 36 per cent. Throughout the years, some of the questions that are key for this paper were either introduced or changed. For the analyses, data from 2006 until 2015 was pooled, as 
comparable questions were asked in these years. This approach allows to estimate robust models that control for period effects.

I restricted the sample to fourth year bachelor (undergraduate) and master (graduate) students, as the spring semester of their fourth year is generally the last year of their educational degree, making it possible to distinguish between students who took part in an exchange programme during their degree and those who did not. The final sample comprises 16,325 respondents. This sample is used to investigate whether the determinants to study abroad differ between male and female students. The final part of the results section, which focuses on the individual — and potentially gendered-motivations of students to study abroad, relies on a cross-sectional sub-sample of 483 respondents. This reduced sample size is due to the fact that questions regarding to the motivation of going abroad were asked only in the Student Monitor 2015.

\section{Variables}

\section{Dependent variables}

The dependent variable measures whether respondents' spent part of their education programme abroad $(0=$ no, $1=$ yes). This variable is based on the question 'During your education in higher education, did you go abroad for study-related activities?' (author's translation from Dutch). Students could indicate whether they participated in study abroad, international internships, language courses, thesis research, summer schools or other reasons related to their educational programme, and they also indicated the number of months they spent abroad. When students reported having been abroad for at least 3 months, they are included in the 'study abroad' group.

\section{Independent variables}

First, given the main focus of this paper on gender and study abroad, gender is included as a dichotomous variable $(0=$ male, $1=$ female $)$. Naturally, an individual's gender is not necessarily related with his/her biological sex, but it is the only available gender variable in the Dutch Student Monitor.

Second, PIT expects 'facilitating conditions' to partly determine educational choices. Consequently, I included parental education level as a proxy for students' socio-economic background as several studies indicated that the propensity to participate in study abroad correlates with parents' educational background (see e.g. Findlay et al. 2006; Netz 2015; Souto Otero et al. 2013), and the studies of Salisbury et al. (2010) and Hurst (2019) indicated this might be particularly relevant for explaining the gender gap in study abroad. I recoded parental educational level into three categories $(1=$ low educational level-primary education, 2 = medium educational level-secondary education, 3 = high educational level-tertiary education).

Third, as indicated above, PIT-researchers generally rely on academic self-concept for analysing students' self-concept. In this study, I rely on the question 'What percentage of chance do you give yourself for completing your degree?' to measure students' subjectively perceived academic self-concept, as I consider this a proxy for students' subjectively perceived ability and skills. Students could indicate a percentage on a 11-point scale, ranging from 0 to $100 \%$. I centred this variable around 0 , with a negative score indicating a negative academic self-concept, and a positive score indicating a positive academic self-concept. 
Fourth, I used a scale of 17 items to measure students' perceived goals, which was reduced through a principal component analysis (PCA) with Varimax rotation and Kaiser Normalization. PCA is a statistical procedure used to uncover the underlying structure of a set of variables without any a priori assumptions about the structure and patterns of the latent dimensions. The items consisted of statements regarding how students perceive themselves in relation to their study (e.g. 'I deliberately chose for a study that allows me to help others later in life' (item 1, author's translation), 'It is important that my study takes as less time as possible away from my leisure time' (item 17, author's translation)). Students could rate each item on a five-point-Likert scale, ranging from 1 ('does not apply to me at all') to 5 ('matches me perfectly'). The Kaiser-Meyer-Olkin measure verified the sampling adequacy for the analysis, $\mathrm{KMO}=0.825$, and all $\mathrm{KMO}$ values for individual items were greater or equal to 0.7. Bartlett's test of sphericity $X^{2}(136)=76,082.397, p<0.001$, indicated that the correlations between the items were sufficiently large for PCA. Four components had eigenvalues over Kaiser's criterion of 1 and in combination explained 57 percent of the variance (see Appendix 1). This is the number of components that are retained for subsequent analyses. The items that cluster on the same component suggest that component 1 represents social goals, component 2 performance goals, component 3 mastery goals and component 4 extrinsic goals. In the multivariate models, I use the regression scores of the four components as independent variables.

Fifth, the Dutch Student Monitor 2015 provided those students who studied abroad 12 statements on the reasons why they did so (e.g. 'To learn to deal with the uncertainties' (item 1, author's' translation), 'To gain professional skills' (item 6, author's translation), 'To gain knowledge of other people and culture' (item 10, author's' translation)). Students could rate these statements on a five-point Likert scale, ranging from 1 ('did not play a role at all') to 5 ('played an important role'). The Kaiser-Meyer-Olkin measure demonstrated adequate sampling again, $\mathrm{KMO}=0.822$. Bartlett's test of sphericity $X^{2}(66)=2871.230$, $p<0.001$, shows that between item correlations are sufficient for the analysis and all KMO values were once again above 0.7 . Similarly to the perceived goals, a PCA with Promax rotation and Kaiser normalization was conducted (see Appendix 2). The analysis uncovered three types of motivation to study abroad. The first component consists of a motivation to challenge oneself, test limitations and explore new possibilities. I labelled this type of motivation as 'Self-development motivations'. The second component covers items that focus on career development, which I consequently label as 'Professionaloriented motivations'. The last component groups items that focus on the exploration of other cultures and people, which I label as 'Exploratory motivations'. In subsequent multivariate analyses, the regression scores of the three components are used.

\section{Control variables}

Several variables that have been shown to correlate with the decision to study abroadand are available in the Dutch Student Monitor for each survey year-are included as control variables. First, I control for three variables which measure barriers to study abroad. Form of education ( $1=$ full-time, $2=$ part-time and $3=$ other (e.g. dual-learning or contract learning)) is included as a categorical variable, as it can be expected thatdue to other commitments such as having a job-non full-time students are less likely to participate in an exchange programme compared with those who follow a full-time study. Having children $(0=$ no, $1=$ yes $)$ and having a disability $(0=$ no, $1=$ yes $)$ have also been documented to be major barriers (see e.g. Netz 2015). For both variables, an extra category 
'missing' has been added in order to keep respondents within the sample, as $30 \%$ did not answer these questions.

Second, I control for two demographic factors. Age is included as a continuous variable, as older students are less likely to study abroad (see e.g. Netz 2015; Netz et al. 2021). Migration background is included as a dichotomous variable based on country of birth ( 0 = no migration background, $1=$ migration background $)$, as often the majority population is more likely to participate in study abroad compared with students with a different ethnic background (Netz et al. 2021). I considered people to have a migration background when his/her birthplace is not the Netherlands, or when either of the parents does not have the Netherlands as his/her birthplace.

Third, I included a categorical variable in order to control for respondents' average grade $(1=$ sufficient, $2=$ good, $3=$ excellent $)$ as Dutch students who have higher academic achievements are more likely to study abroad (Van Mol et al. 2020).

Fourth, study field is included as a categorical variable, as participation in study abroad varies across educational disciplines (see e.g. Netz 2015) and in some disciplines such as Humanities and the Social Sciences, female students are generally overrepresented. Furthermore, several studies suggest that the gender gap in study abroad can partly be explained by compositional gender differences across disciplines (Hurst 2019; Netz et al. 2021).

Finally, I control for period effects by including a continuous variable indicating the year of the survey.

\section{Analytic strategy}

First, descriptive statistics provide preliminary insights into differences between female and male students' in hypothesised study abroad determinants. Second, I use step-wise logistic regression models to investigate the relationship between the different components of Personal Investment Theory and study abroad decisions. Finally, multivariate analysis of variance (MANOVA) is used to investigate differences in study abroad motivations across gender.

\section{Results}

\section{Descriptive statistics}

The descriptive statistics (see Table 1) show that there is a statistically significant difference between female and male students regarding study abroad participation: $29.6 \%$ of female students participated compared with $27.5 \%$ of male students $\left(\chi^{2}=8.18, p<0.01\right)$. Regarding facilitating conditions, the parents of female students have higher educational attainment levels $\left(\chi^{2}=9.06, p<0.05\right.$ for educational level father, $\chi^{2}=35.25, p<0.001$ for educational level mother), which is in line with my expectations. The results for academic self-concept are also in line with my expectations, as no significant differences were detected between female and male students. Regarding students' perceived goals, the descriptive findings reveal that female students are more likely to score high on social $(t(16,216)=-23.982, p<0.001)$, performance $(t(16,216)=-8.685, p<0.001)$ and mastery $(t(16,216)=-3.719, p<0.001)$ goal orientation compared with male students, and they are less likely to score high on extrinsic goals $(t(16,216)=20.604, p<0.001)$. 
Table 1 Descriptive overview of all variables by gender

\begin{tabular}{|c|c|c|c|c|c|c|c|c|}
\hline & \multicolumn{4}{|l|}{ Female } & \multicolumn{4}{|l|}{ Male } \\
\hline & Mean & SD & Range & Number & Mean & SD & Range & Number \\
\hline Age $* * *$ & 24.97 & 6.45 & $17-89$ & 9,319 & 26.19 & 7.40 & $16-74$ & 7,015 \\
\hline Academic self-concept & 4.63 & 0.95 & $-5-5$ & 9,309 & 4.58 & 1.05 & $-5-5$ & 7,015 \\
\hline \multicolumn{9}{|l|}{ Perceived goals } \\
\hline Social*** & 0.16 & 0.96 & $-3.43-2.40$ & 9,242 & -0.21 & 1.02 & $-3.42-2.26$ & 6,976 \\
\hline Performance $* * *$ & 0.06 & 0.96 & $-4.34-2.61$ & 9,242 & -0.08 & 1.04 & $-6.08-2.45$ & 6,976 \\
\hline Mastery*** & 0.03 & 0.98 & $-3.55-2.66$ & 9,242 & -0.03 & 1.02 & $-3.92-2.75$ & 6,976 \\
\hline Extrinsic*** & -0.14 & 0.97 & $-3.06-2.90$ & 9,242 & 0.18 & 1.01 & $-3.12-2.98$ & 6,976 \\
\hline \multicolumn{9}{|l|}{ Study Abroad Motivations } \\
\hline $\begin{array}{l}\text { Self-development } \\
\text { motivations }\end{array}$ & 0.05 & 0.97 & $-2.43-1.45$ & 279 & -0.07 & 1.04 & $-2.43-1.47$ & 204 \\
\hline $\begin{array}{l}\text { Professional-oriented } \\
\text { motivations }\end{array}$ & 0.03 & 1.04 & $-3.05-1.54$ & 279 & -0.04 & 0.95 & $-2.99-1.54$ & 204 \\
\hline \multirow{2}{*}{$\begin{array}{l}\text { Exploratory motiva- } \\
\text { tions* }\end{array}$} & 0.08 & 0.95 & $-2.92-1.27$ & 279 & -0.11 & 1.06 & $-2.97-1.18$ & 204 \\
\hline & & $\%$ & Range & $\mathrm{N}$ & & $\%$ & Range & $\mathrm{N}$ \\
\hline Study abroad?** & & & $0-1$ & 8,986 & & & $0-1$ & 6,791 \\
\hline No & & 70.4 & & 6,326 & & 72.5 & & 4,922 \\
\hline Yes & & 29.6 & & 2,660 & & 27.5 & & 1,869 \\
\hline Average grade $* * *$ & & & $1-3$ & 8,277 & & & $1-3$ & 6,474 \\
\hline Sufficient & & 25.7 & & 2,126 & & 32.2 & & 2,086 \\
\hline Good & & 71.2 & & 5,890 & & 65.0 & & 4,209 \\
\hline Excellent & & 3.2 & & 261 & & 2.8 & & 179 \\
\hline Educational level father* & & & $1-3$ & 8,757 & & & $1-3$ & 6,586 \\
\hline Low & & 25.0 & & 2,189 & & 26.3 & & 1,734 \\
\hline Medium & & 34.6 & & 3,028 & & 32.3 & & 2,129 \\
\hline High & & 40.4 & & 3,540 & & 41.3 & & 2,723 \\
\hline $\begin{array}{l}\text { Educational level } \\
\text { mother*** }\end{array}$ & & & $1-3$ & 8,888 & & & $1-3$ & 6,620 \\
\hline Low & & 31.4 & & 2,792 & & 36.0 & & 2,380 \\
\hline Medium & & 37.0 & & 3,289 & & 34.4 & & 2,275 \\
\hline High & & 31.6 & & 2,807 & & 29.7 & & 1,965 \\
\hline Migration background & & & $0-1$ & 9,147 & & & $0-1$ & 6,897 \\
\hline No & & 91.1 & & 8,332 & & 91.7 & & 6,323 \\
\hline Yes & & 8.9 & & 815 & & 8.3 & & 574 \\
\hline Disability?*** & & & $1-3$ & 9,310 & & & $1-3$ & 7,015 \\
\hline No & & 61.6 & & 5,732 & & 58.7 & & 4,118 \\
\hline Yes & & 8.4 & & 781 & & 5.2 & & 367 \\
\hline Missing & & 30.0 & & 2,797 & & 36.1 & & 2,530 \\
\hline Children?*** & & & $1-3$ & 9,310 & & & $1-3$ & 7,015 \\
\hline No & & 65.3 & & 6,078 & & 57.4 & & 4,029 \\
\hline Yes & & 4.7 & & 441 & & 6.6 & & 464 \\
\hline Missing & & 30.0 & & 2,791 & & 36.0 & & 2,522 \\
\hline Form of education*** & & & $1-3$ & 9,310 & & & $1-3$ & 7,015 \\
\hline Full-time & & 89.3 & & 8,313 & & 86.6 & & 6,077 \\
\hline Part-time & & 10.1 & & 936 & & 12.3 & & 866 \\
\hline
\end{tabular}


Table 1 (continued)

\begin{tabular}{|c|c|c|c|c|c|c|c|c|}
\hline & \multicolumn{4}{|l|}{ Female } & \multicolumn{4}{|l|}{ Male } \\
\hline & Mean & SD & Range & Number & Mean & SD & Range & Number \\
\hline Other & & 0.7 & & 61 & & 1.0 & & 72 \\
\hline Study Field*** & & & $1-10$ & 9,303 & & & $1-10$ & 7,006 \\
\hline Agriculture & & 5.2 & & 483 & & 7.4 & & 519 \\
\hline Nature & & 2.1 & & 199 & & 4.6 & & 323 \\
\hline Technic & & 6.3 & & 588 & & 28.3 & & 1,981 \\
\hline Healthcare & & 16.5 & & 1,539 & & 4.4 & & 311 \\
\hline Economics & & 18.6 & & 1,730 & & 27.1 & & 1,897 \\
\hline Law & & 3.7 & & 348 & & 3.5 & & 246 \\
\hline Behaviour and society & & 23.4 & & 2,177 & & 9.7 & & 680 \\
\hline Language and culture & & 11.5 & & 1,067 & & 7.3 & & 514 \\
\hline Education & & 12.2 & & 1,136 & & 7.0 & & 492 \\
\hline Sector transparent & & 0.4 & & 36 & & 0.6 & & 43 \\
\hline Survey year*** & & & $1-9$ & 9,310 & & & $1-9$ & 7,015 \\
\hline 2006 & & 7.9 & & 740 & & 10.6 & & 744 \\
\hline 2007 & & 7.9 & & 733 & & 9.3 & & 650 \\
\hline 2008 & & 7.0 & & 656 & & 7.9 & & 552 \\
\hline 2009 & & 7.1 & & 662 & & 8.2 & & 576 \\
\hline 2011 & & 17.3 & & 1,609 & & 17.8 & & 1,250 \\
\hline 2012 & & 8.9 & & 830 & & 8.0 & & 562 \\
\hline 2013 & & 15.8 & & 1,467 & & 14.1 & & 988 \\
\hline 2014 & & 12.7 & & 1,185 & & 10.2 & & 716 \\
\hline 2015 & & 15.3 & & 1,428 & & 13.9 & & 977 \\
\hline
\end{tabular}

Source: Dutch Student Monitor 2006-2015

Standard deviations shown where appropriate. Statistically significant differences between male and female respondents were measured by $t$ tests for continuous variables and chi-square for categorical variables. As an exception, the variable "survey year" was measured with $t$ test as we use it as a continuous variable, but we present the different categories in the table as to inform the reader about the distribution of respondents across survey years

$* p<0.05 ; * * p<0.01 ; * * * p<0.001$

The finding on higher scores on social goals is also in line with my expectations. Finally, considering students' motivations to study abroad, it can be observed that female students are more likely to score higher on the 'exploratory motivations' compared with male students $(t(481)=-2.068, p<0.05)$. No statistically significant differences between female and male students are observed for 'self-development motivations' and 'professional-oriented motivations'.

The descriptive analysis also revealed differences between female and male students considering several control variables. Female students in the sample are significantly younger compared with the male students $(t(16,323)=11.276, p<0.001)$, and they generally have better grades $\left(\chi^{2}=76.23, p<0.001\right)$. Furthermore, statistically significant differences between both groups are also detected regarding disability $\left(\chi^{2}=106.62, p<0.001\right)$ and having children $\left(\chi^{2}=109.12, p<0.001\right)$. As a robustness check, I ran an additional analysis without the 'missing' category. The results remain statistically significant. Female students are less likely to have children $\left(\chi^{2}=44.749, p<0.001\right)$, but more often have a disability 
$\left(\chi^{2}=41.210, p<0.001\right)$. In addition, the female students in the sample are significantly more likely to follow full-time education $\left(\chi^{2}=29.009, p<0.001\right)$; they are more often studying study fields wherein it is more common to study abroad, such as the Social Sciences and Arts $\left(\chi^{2}=2587.415, p<0.001\right)$; and the participation in the Dutch Student Monitor also varied across years $(t(16,323)=-8.827, p<0.001)$. Finally, no differences could be detected regarding migration background between female and male students.

\section{Multivariate analyses}

\section{Personal Investment Theory and the propensity to study abroad}

Next, I present binary logistic regressions on the propensity to study abroad in Table 2.

Model I reveals that female students are significantly more likely to study abroad after controlling for possible confounders. In model II, I added facilitating conditions, namely parental educational level. The results show that particularly the educational level of mothers is associated with a higher propensity to participate in study abroad. Model III investigates the correlation between academic self-concept and study abroad and indicates that students who score higher on academic self-concept are more likely to study abroad. In model IV, I focus on students' perceived goals, and a statistically significantly correlation between performance goals and study abroad is observed. For social goals, mastery goals and extrinsic goals, no such association is detected. The full model (model V) confirms these associations: female students are more likely to study abroad, as well as students who have a mother with a higher educational level. Furthermore, students who are more inclined towards performance and mastery goals during their higher education degree have a higher propensity to study abroad.

Although the analysis in Table 2 provides insight into the association between the three main elements of Personal Investment Theory and study abroad decisions, it does not indicate whether these elements play a different role for male and female students. Therefore, I investigate interaction effects in Table 3. The results provide little support for the proposition that the elements of PIT can explain the gender gap in study abroad: I only find a negative association between the interaction effects of gender with mastery goals on study abroad decisions. This means that female students who score less high on a mastery goal orientation are more likely to study abroad.

\section{Gender differences in motivations to go abroad}

In a final analytical step, I only focus on those students who indicated to have participated in international exchange programmes in the 2015 survey. When descriptively analyzing the differences between male and female students on the three types of motivation (see Table 1), I only observe a statistically significant difference in terms of exploratory motivations, with female students being more likely to score high on this type of motivation. I further investigated these three types of motivations with a MANOVA-model, which allows to control for the correlation between the dependent variables. This is important, as students might be motivated to study abroad by a combination of these types of motivation-i.e. it is highly likely they are interrelated. The analysis showed no differences between female and male students on the combined types of motivations $(F(3,479)=1.445, p=0.229$, Wilks' $\Lambda=0.991)$. However, as female participants appear to be more often supported by their families in their decision 


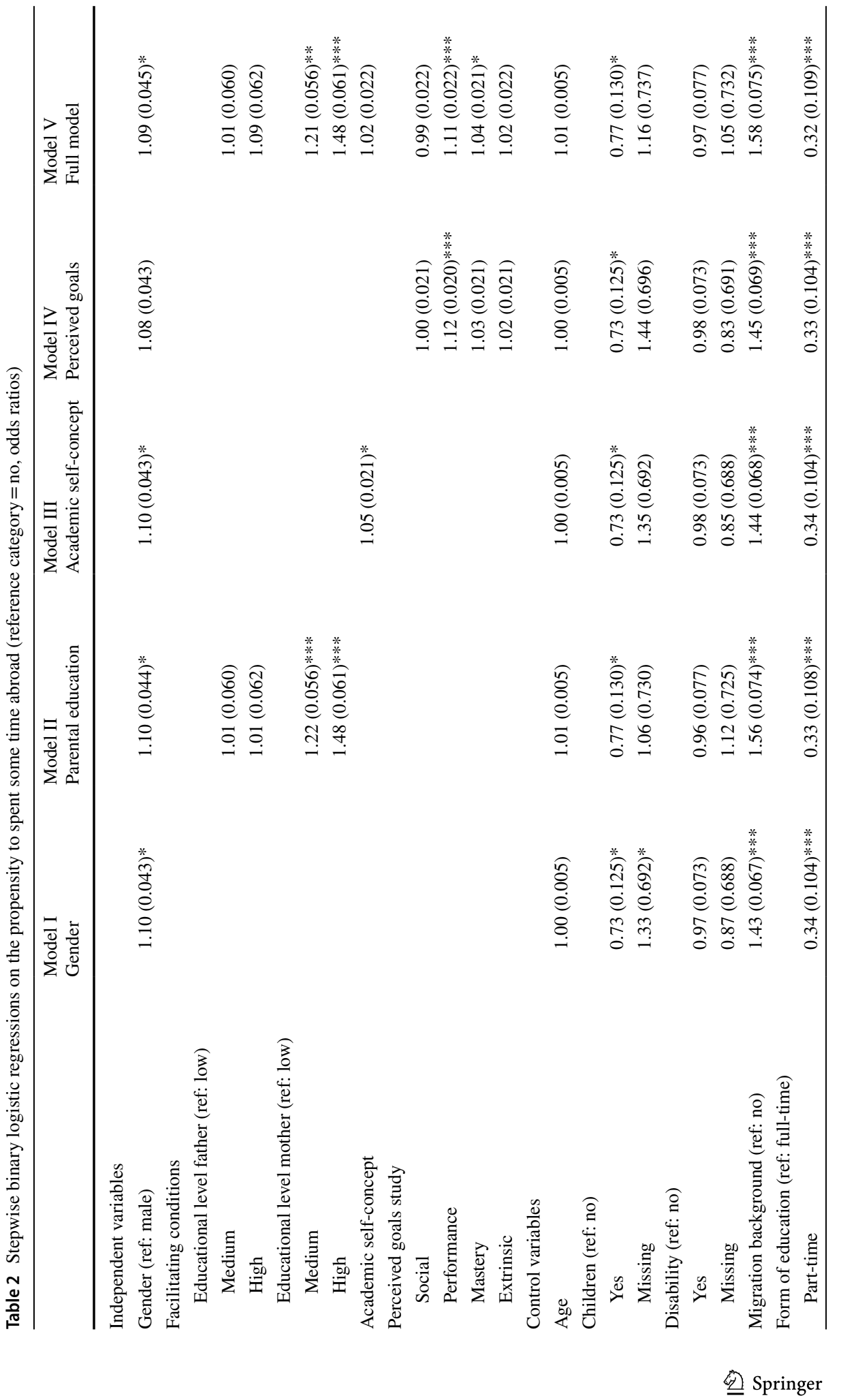




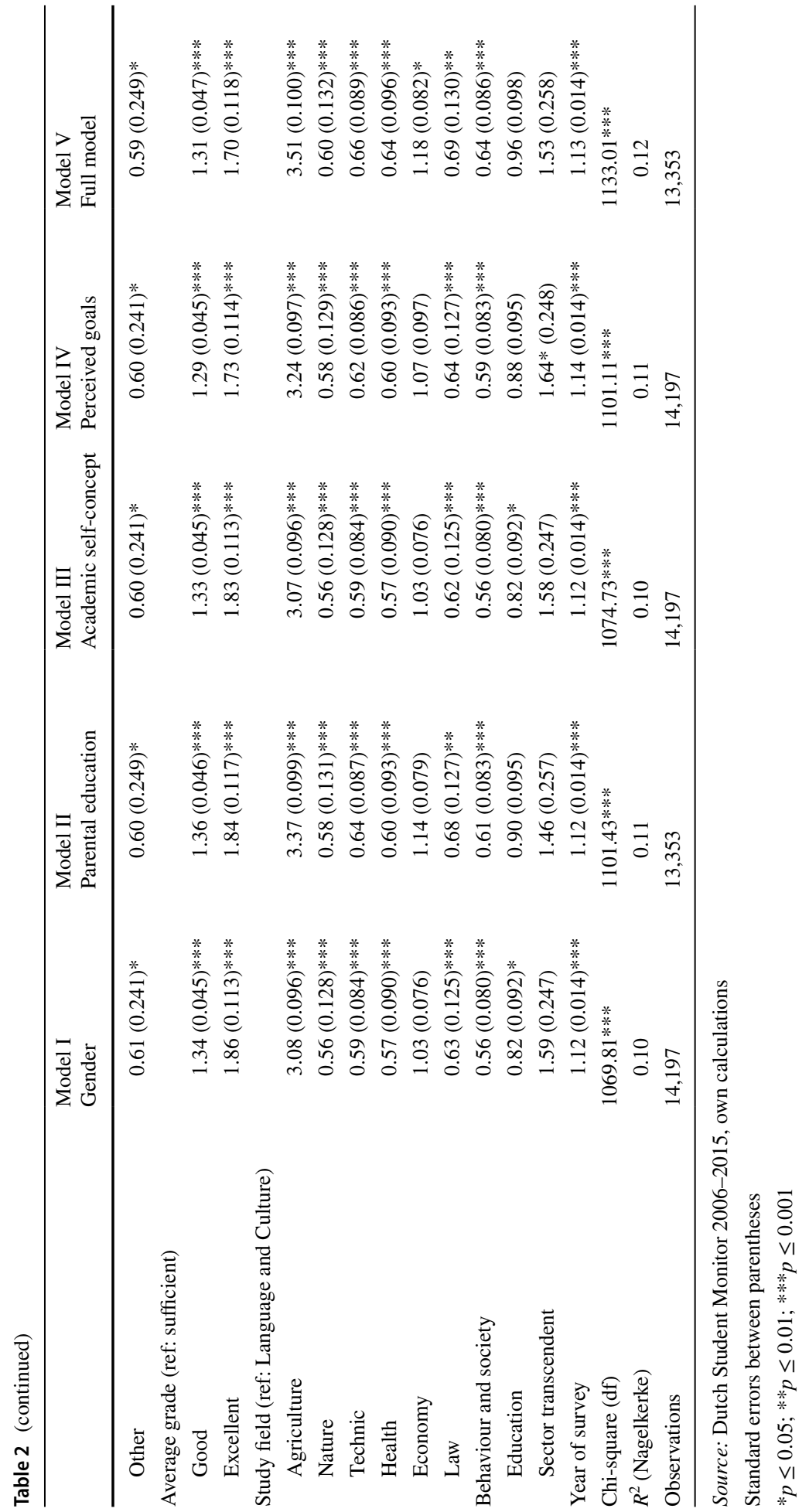




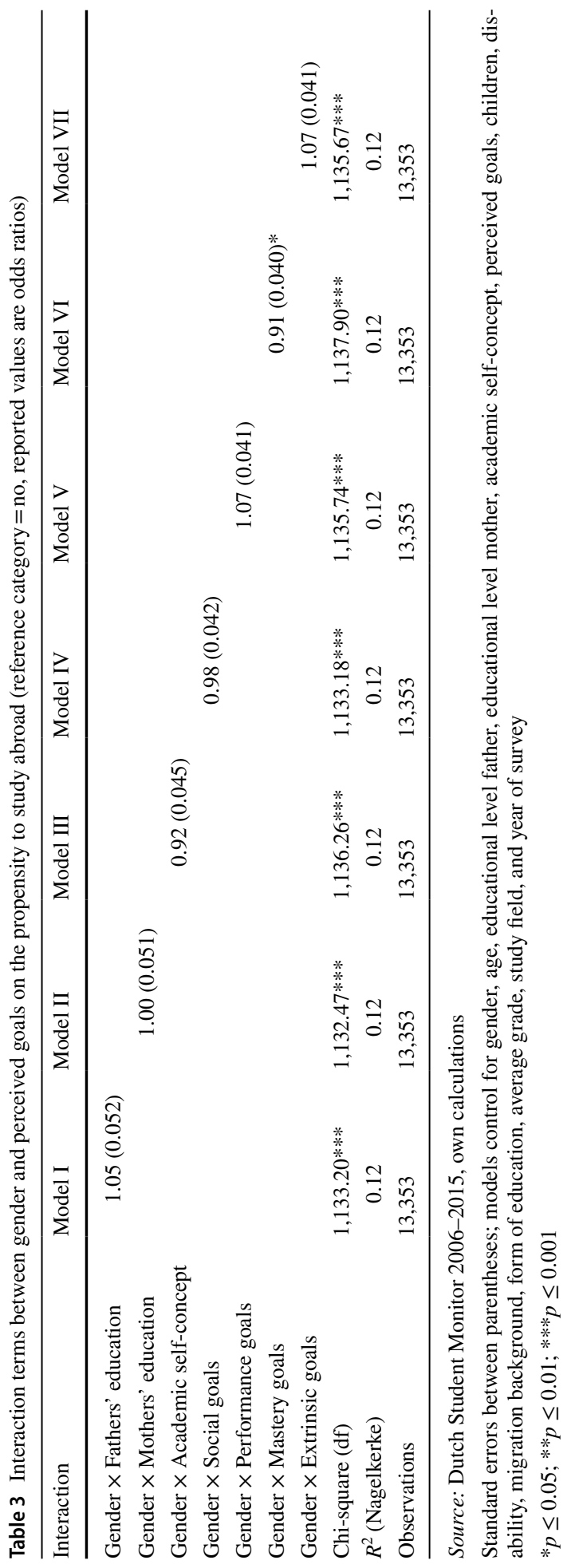


or intention to study abroad (Netz et al. 2021; Shirley 2006), which would particularly hold true for families in the upper class (Hurst 2019; Netz et al. 2021), I also investigated whether gender differences in combined study abroad motivations correlate with the socio-economic profile of their parents. Here, the MANOVA-analysis revealed a statistically significant correlation between the educational level of mothers and the combined types of motivation $(F(6,908)=2.384, p<0.05$, Wilks' $\Lambda=0.969)$, as well as a significant interaction effect between gender and the educational level of the mother on the combined types of motivation $(F(6,908)=2.957, p<0.01$, Wilks' $\Lambda=0.962)$, but not for the fathers $(F(6,886)=0.540$, $p=0.778$, Wilks' $\Lambda=0.988$ ). When exploring this finding further, it can be observed that these findings particularly relate to the relationship between the educational level of mothers and exploration motivations for both male and female students $(F(2,462)=6.778, p<0.05)$ as well as professional motivations to study abroad among female students $(F(2,462)=2.767$, $p<0.10)$. To further interpret this result, I present plots with the estimated marginal means for each type of motivation in Fig. 1. Figure 1c indicates exploration motivations are more likely to be present among - female and male - students who have a mother with a medium-level education. Finally, Fig. 1 b clearly shows that female students with mothers with a low education are much more likely to score high on professional development motivations.

\section{Discussion and conclusion}

In this paper, I aimed to shed light on potential mechanisms that can explain the gender gap in study abroad. I therefore started from Personal Investment Theory, which focuses on the determinants of educational decisions. The analysis was based on the Dutch Student Monitor, covering a period of ten years, namely 2006-2015. Based on the presented results, four main conclusions can be drawn.

First, the findings extend the few existing empirical studies on the gender gap in study abroad beyond the USA, confirming that also in the Dutch context, female students are more likely to study abroad when controlling for confounding variables that are often put forward as explanations for the existence of this gender gap, such as overrepresentation of male/female students in certain study fields and programmes wherein study abroad is more common.

Second, in line with earlier studies the importance of parental educational levels in determining participation in study abroad came strongly forward. Maternal educational attainment levels seem to be particularly relevant in explaining study abroad decisions as well as - potentially - the gender gap in study abroad. The presented results on the determinants of study abroad decisions showed that the higher the educational level of the mother, the
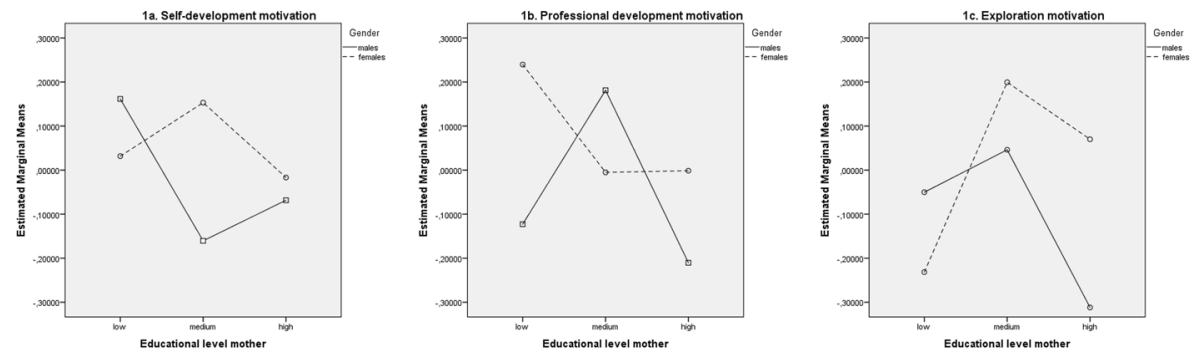

Fig. 1 Estimated marginal means for the interaction between gender and educational level mother 
more likely it is - both female and male - students study abroad. This finding is in line with scholarly literature that highlights the role of mothers' educational attainment on children's educational outcomes (e.g. Roksa and Potter 2011).

Third, the results showed that students who score higher on performance and mastery goals for their higher education trajectory are also more likely to study abroad. This means these students might be more inclined to study abroad because of an intrinsic interest in following their personal interest and the aim to do well in education-i.e. they might be high achievers. Interestingly, however, when investigating interaction effects between gender and perceived goals, no significant association with study abroad decisions is detected, except for female students and mastery goals, with female students who score lower on mastery goals being more likely to study abroad. However, as no significant patterns have been detected for the other goal variables, I hypothesise this to be a spurious relationship.

Fourth, the results on study abroad motivations which focused on a more restricted sample of Dutch higher education students in the 2015 Student Monitor suggested again the importance of maternal educational attainment levels, both for male and female students. Interestingly, the results particularly suggest exploration motivations to occur more likely among students with mothers with a medium educational attainment level. This might indicate 'social spiralist' (Favell and Recchi 2011) ideals, whereby these mothers encourage their offspring to study abroad in order to explore the world and have an experience which might lead to social mobility, whereas the children of more highly educated mothers might have more routine access to international experiences. Furthermore, the finding that particularly female students are more motivated by exploration motivations compared with their male counterparts is in line with the results of Tompkins et al. (2017), who indicated that 'women are generally more interested in learning about new cultures, while men are more focused on fulfilling the (perceived) expectation to become successful breadwinners by seeking a speedy labour market entry, instead of running the risk of prolonging their studies through studying abroad'. In addition, the analyses add some further nuance to American studies on the gender gap in study abroad (Hurst 2019; Salisbury et al. 2010), as the findings suggest that beyond general parental education levels, it is particularly maternal educational level that matters for female students. The results indicated a statistically significant correlation between lower levels of maternal education with professional motivations to study abroad among female students. Such finding corresponds with broader social reproduction studies which show that same-sex parental education significantly influences students' educational expectations (e.g. Buchmann and DiPrete 2006; Mahaffy and Ward 2002; Wells et al. 2011). The results thus suggest that lower educated mothers might place more emphasis on the potential professional benefits of participating in study abroad to their daughters, whereas for male students such emphasis might be less presentalso not from the fathers. This finding is in line with studies which showed that parents are generally less involved in the academic life of sons compared with daughters (Carter and Wojtkiewicz 2000), and women experience a larger effect of parental involvement on their educational expectations (Reynolds and Burge 2008; Wells et al. 2011). Future research, both quantitative and qualitative, could further elaborate on the mechanisms behind maternal education levels and motivations to study abroad. However, particularly qualitative research, whereby parents of male and female students are interviewed, could be informative to explore these mechanisms more in-depth.

Finally, the limitations of my analysis should be mentioned, which particularly relate to the fact that the analysis relied on secondary data. In order to fully test Personal Investment Theory in relation to the study abroad decision-making process, it would be relevant to also have data on other variables that show to be important in defining educational decisions as well 
as study abroad decisions. For example, research on the determinants of study abroad clearly indicated peers as well as wider economic, educational, and political contexts play a significant role in study abroad decisions (e.g. Beerkens et al. 2016; Brooks and Waters 2021; Luo and Jamieson-Drake 2015; Rodríguez González et al. 2011). As such, it would be relevant to have access to data on peer relationships as well as contextual characteristics. Unfortunately, such information was not available in the Dutch Student Monitor. In addition, future research could also more explicitly focus on students' gender norms and anticipated life-courses. It is plausible that female students are more likely to participate in international student exchanges because they anticipate this to be the ideal moment in their life-course as they are generally freer from family constraints. When looking at academic mobility at the postgraduate level, for example, it is interesting to see how the gender gap is reversed, i.e. male doctoral students are more likely to be internationally mobile (OECD 2020). This suggests the specific life-course phase an individual is in, as well as gendered expectations regarding their future, might play an important role in explaining the gender gap in study abroad. Qualitative research might be particularly informative here. Finally, the measurements of academic self-concept and perceived goals are not precise measurements of these psychological constructs. Future research could focus on a more thorough application of PIT on study abroad decisions of male and female students, most likely through new survey designs.

Acknowledgements I would like to express my sincere thanks to Tina Kipshidze for helping me during her internship with the preparation of the database and initial analyses.

\section{Compliance with ethical standards}

Research ethics and data statement This paper is based on anonymized secondary data, downloaded from the Data Archiving and Networked Services (DANS). As such, no ethical approval was needed by an institutional board. Permission to download the data to be used for this paper was granted by email on 25 September 2018 by DANS. A data package with the dataset and syntaxes is stored at Surfdrive. Both the author of this article and the head of his department have access to this package. As restrictions apply to the availability of the original data, which were used under license for the current paper, the data are available from the author upon reasonable request, conditional on permission of DANS.

Open Access This article is licensed under a Creative Commons Attribution 4.0 International License, which permits use, sharing, adaptation, distribution and reproduction in any medium or format, as long as you give appropriate credit to the original author(s) and the source, provide a link to the Creative Commons licence, and indicate if changes were made. The images or other third party material in this article are included in the article's Creative Commons licence, unless indicated otherwise in a credit line to the material. If material is not included in the article's Creative Commons licence and your intended use is not permitted by statutory regulation or exceeds the permitted use, you will need to obtain permission directly from the copyright holder. To view a copy of this licence, visit http://creativecommons.org/licenses/by/4.0/.

\section{Appendix 1. Exploratory factor analysis on students' study motivation $(n=16,218)$}

\begin{tabular}{lccccccc}
\hline \multirow{2}{*}{ Item } & \multicolumn{6}{l}{ Rotated factor loadings } & \\
\cline { 2 - 5 } & $C 1$ & $C 2$ & $C 3$ & \multirow{2}{*}{$C 4$} & & Communalities \\
\hline Help others through education & 0.765 & 0.065 & 0.114 & 0.086 & 0.622 \\
Contribute to society & 0.756 & 0.120 & 0.061 & 0.090 & 0.609 \\
\hline
\end{tabular}




\begin{tabular}{|c|c|c|c|c|c|}
\hline \multirow[b]{2}{*}{ Item } & \multicolumn{4}{|c|}{ Rotated factor loadings } & \multirow[b]{2}{*}{ Communalities } \\
\hline & $C 1$ & $C 2$ & $C 3$ & $C 4$ & \\
\hline By studying helping others & 0.752 & -0.118 & 0.205 & -0.020 & 0.609 \\
\hline Do something back for society & 0.735 & 0.186 & 0.060 & 0.176 & 0.598 \\
\hline $\begin{array}{l}\text { Helpful for society, more important than high } \\
\text { salary }\end{array}$ & 0.703 & 0.027 & 0.083 & -0.233 & 0.557 \\
\hline Passion for the subject & 0.155 & 0.163 & 0.822 & -0.038 & 0.727 \\
\hline Knowledge and insights for future profession & 0.210 & 0.407 & 0.565 & 0.143 & 0.549 \\
\hline Always been interested in subject & 0.080 & -0.081 & 0.799 & 0.051 & 0.654 \\
\hline Outside study also involved in subject & 0.117 & 0.279 & 0.686 & 0.007 & 0.562 \\
\hline Studying is developing broadly & 0.256 & 0.695 & 0.106 & 0.249 & 0.622 \\
\hline Studying is self-development & 0.210 & 0.681 & 0.128 & 0.248 & 0.586 \\
\hline Studying is a necessary evil & 0.038 & -0.640 & -0.017 & 0.227 & 0.463 \\
\hline Studying is about matching expectations & 0.080 & -0.476 & -0.177 & 0.288 & 0.347 \\
\hline Study should take as less leisure time as possible & 0.006 & -0.569 & -0.127 & 0.218 & 0.388 \\
\hline Through study I secure a job & -0.055 & -0.138 & 0.000 & 0.738 & 0.566 \\
\hline Study opens doors to get a job with prestige & -0.015 & 0.021 & 0.056 & 0.809 & 0.658 \\
\hline It is important study gets respect in society & 0.136 & -0.044 & 0.052 & 0.739 & 0.570 \\
\hline Eigenvalues & 4.083 & 2.327 & 1.887 & 1.392 & \\
\hline$\%$ of variance & 24.02 & 13.69 & 11.10 & 8.19 & \\
\hline Cronbach's $\alpha$ & 0.810 & 0.669 & 0.754 & 0.714 & \\
\hline
\end{tabular}

Based on the question: 'Which of the following statements fit the way you perceive your study?' Extraction method: principal component analysis. Rotation method: Varimax with Kaiser Normalization. Factor loadings over 0.40 appear in italics

\section{Appendix 2. Exploratory factor analysis on students' motivation to go abroad $(n=483)$}

\begin{tabular}{|c|c|c|c|c|}
\hline \multirow[b]{2}{*}{ Item } & \multicolumn{3}{|c|}{ Pattern matrix } & \multirow[b]{2}{*}{ Communalities } \\
\hline & $C 1$ & $C 2$ & $C 3$ & \\
\hline Dealing with uncertainties & 0.913 & -0.049 & -0.085 & 0.739 \\
\hline Understand own possibilities and limitations & 0.829 & 0.086 & 0.009 & 0.741 \\
\hline Become more independent & 0.833 & -0.057 & 0.052 & 0.720 \\
\hline Function in unknown situation & 0.804 & 0.025 & 0.104 & 0.759 \\
\hline Acquire academic skills & -0.102 & 0.789 & -0.015 & 0.588 \\
\hline Gaining professional skills & 0.027 & 0.817 & -0.063 & 0.661 \\
\hline Insight into other teaching methods & -0.081 & 0.730 & 0.145 & 0.560 \\
\hline Broad view into the profession I want to practice & 0.041 & 0.772 & -0.055 & 0.598 \\
\hline Insight into my (international) career opportunities & 0.122 & 0.664 & 0.145 & 0.498 \\
\hline Knowledge and understanding of other culture & -0.021 & -0.027 & 0.957 & 0.885 \\
\hline Dealing with people from other culture & -0.022 & 0.015 & 0.941 & 0.871 \\
\hline Improve language skills & 0.173 & 0.013 & 0.529 & 0.412 \\
\hline Eigenvalues & 4.575 & 2.374 & 1.084 & \\
\hline$\%$ of variance & 38.124 & 19.786 & 9.030 & \\
\hline
\end{tabular}


Pattern matrix

\begin{tabular}{|c|c|c|c|c|}
\hline Item & $C 1$ & $C 2$ & $C 3$ & Communalities \\
\hline Cronbach's $\alpha$ & 0.880 & 0.819 & 0.776 & \\
\hline
\end{tabular}

Based on the question: 'Why did you go abroad or do you want to go abroad?' Extraction method: principal component analysis. Rotation method: Promax with Kaiser Normalization. Factor loadings over 0.40 appear in italics

\section{References}

Ackerman, P. L., Kanfer, R., \& Beier, M. E. (2013). Trait complex, cognitive ability, and domain knowledge predictors of baccalaureate success, STEM persistence, and gender differences. Journal of Educational Psychology, 105(3), 911-927.

Awad, G. H. (2007). The role of racial identity, academic self-concept, and self-esteem in the prediction of academic outcomes for african american students. Journal of Black Psychology, 33(2), 188-207.

Beerkens, M., Souto-Otero, M., de Wit, H., \& Huisman, J. (2016). Similar students and different countries? An analysis of the barriers and drivers for erasmus participation in seven countries. Journal of Studies in International Education, 20(2), 184-204.

Böttcher, L., Araújo, N. A. M., Nagler, J., Mendes, J. F. F., Helbing, D., \& Herrmann, H. J. (2016). Gender gap in the ERASMUS mobility program. PLOS ONE, 11(2), e0149514.

Brooks, R., \& Waters, J. (2021). Decision-making: spatio-temporal contexts of decision-making in education abroad, in A. Ogden, B. Streitwieser, and C. Van Mol, (eds.), Education Abroad. Bridging Scholarship and Practice. Oxon \& New York: Routledge, pp. 15-27.

Buchmann, C., \& DiPrete, T. A. (2006). The growing female advantage in college completion: the role of family background and academic achievement. American Sociological Review, 71(4), 515-541.

Carter, R. S., \& Wojtkiewicz, R. A. (2000). Parental involvement with adolescents' education: do daughters or sons get more help? Adolescence, 35(137), 29-44.

Cokley, K., Awad, G., Smith, L., Jackson, S., Awosogba, O., \& Hurst, A. (2015). The roles of gender stigma consciousness, impostor phenomenon and academic self-concept in the academic outcomes of women and men. Sex Roles, 73(9), 414-426.

Cokley, K., \& Patel, N. (2007). A psychometric investigation of the academic self-concept of Asian American College Students. Educational and Psychological Measurement, 67(1), 88-99.

European Commission. (2017). Who were the average Erasmus + higher education students in 2015-16? Infographics package Erasmus + annual report 2016 Brussels: European Commission.

Favell, A., \& Recchi, E. (2011). Social mobility and spatial mobility, in A. Favell and V. Guiraudon, (eds.), Sociology of the European Union. Basingstoke \& New York: Palgrave Macmillan, pp. 50-75.

Findlay, A. M., King, R., Stam, A., \& Ruiz-Gelices, E. (2006). Ever reluctant europeans: the changing geographies of UK students studying and working abroad. European Urban and Regional Studies, 13(4), 291-318.

Hurst, A. L. (2019). 'Class and gender as predictors of study abroad participation among US liberal arts college Students.' Studies in Higher Education, 44(7), 1241-1255.

Institute of International Education. (2017). Profile of U.S. study abroad students, 2004/05-2015/16. Open Doors Report on International Educational Exchange.

Isiksal, M. (2010). A comparative study on undergraduate students' academic motivation and academic self-concept. The Spanish Journal of Psychology, 13(2), 572-585.

Kadir, M. S., \& Yeung, A. S. (2016). Academic self-concept. In V. Zeigler-Hill \& T. K. Shackelford (Eds.), Encyclopedia of Personality and Individual Differences (pp. 1-8). Cham: Springer International Publishing.

Kim, R. I., \& Goldstein, S. B. (2005). Intercultural attitudes predict favorable study abroad expectations of U.S. college students. Journal of Studies in International Education, 9(3), 265-278.

King, R., \& Raghuram, P. (2013). International student migration: mapping the field and new research agendas. Population, Space and Place, 19(2), 127-137.

King, R. B., Yeung, S.S.-S., \& Cai, Y. (2019). Personal investment theory: a multi-faceted framework to understand second and foreign language motivation. System, 86, 102123. 
Litalien, D., Morin, A. J. S., \& McInerney, D. M. (2017). Achievement goal profiles among adolescent males and females. Developmental Psychology, 53(4), 731-751.

Lörz, M., Netz, N., \& Quast, H. (2016). Why do students from underprivileged families less often intend to study abroad? Higher Education, 72(2), 153-174.

Luo, J., \& Jamieson-Drake, D. (2015). Predictors of study abroad intent, participation, and college outcomes. Research in Higher Education, 56(1), 29-56.

Mahaffy, K. A., \& Ward, S. K. (2002). The gendering of adolescents' childbearing and educational plans: reciprocal effects and the influence of social context. Sex Roles, 46(11), 403-417.

Meece, J. L., Glienke, B. B., \& Burg, S. (2006). Gender and motivation. Journal of School Psychology, 44(5), 351-373.

Netz, N. (2015). What deters students from studying abroad. evidence from four European countries and its implications for higher education policy. Higher Education Policy, 28(2), 151-174.

Netz, N., Barker, M., Entrich, S., \& Klasik, D. (2021). Socio-demographics: a global overview of inequalities in education abroad participation, in A. Ogden, B. Streitwieser, and C. Van Mol, (eds.), Education Abroad. Bridging Scholarship and Practice. Oxon \& New York: Routledge, pp. 28-42.

OECD. (2020). Education at a glance 2020. OECD Indicators: OECD Publishing.

Presley, A., Damron-Martinez, D., \& Zhang, L. (2010). A study of business student choice to study abroad: a test of the theory of planned behavior. Journal of Teaching in International Business, 21(4), 227-247.

Redden, E. (2008). Women abroad and men at home Inside Higher Ed. City.

Reynolds, J. R., \& Burge, S. W. (2008). Educational expectations and the rise in women's post-secondary attainments. Social Science Research, 37(2), 485-499.

Rodríguez González, C., Bustillo Mesanza, R., \& Mariel, P. (2011). The determinants of international student mobility flows: an empirical study on the Erasmus programme. Higher Education, 62(4), 413-430.

Roksa, J., \& Potter, D. (2011). Parenting and academic achievement: intergenerational transmission of educational advantage. Sociology of Education, 84(4), 299-321.

Salisbury, M. H., Paulsen, M. B., \& Pascarella, E. T. (2010). To see the world or stay at home: applying an integrated student choice model to explore the gender gap in the intent to study abroad. Research in Higher Education, 51(7), 615-640.

Shirley, S. W. (2006). The gender gap in post-secondary study abroad: understanding and marketing to male students. Grand Forks: University of North Dakota.

Souto Otero, M., Huisman, J., Beerkens, M., De Wit, H., \& Vujić, S. (2013). Barriers to international student mobility: evidence from the Erasmus Program. Educational Researcher, 42(2), 70-77.

Thiele, T., Singleton, A., Pope, D., \& Stanistreet, D. (2015). Predicting students' academic performance based on school and socio-demographic characteristics. Studies in Higher Education, 41(8), 1424-1446.

Tompkins, A., Cook, T., Miller, E., \& LePeau, L. A. (2017). Gender influences on students' study abroad participation and intercultural competence. Journal of Student Affairs Research and Practice, 54(2), 204-216.

Van Mol, C., Caarls, K., \& Souto-Otero, M. (2020). International student mobility and labour market outcomes: an investigation of the role of level of study, type of mobility, and international prestige hierarchies. Higher Education.

Wells, R. S., Seifert, T. A., Padgett, R. D., Park, S., \& Umbach, P. D. (2011). Why do more women than men want to earn a four-year degree? exploring the effects of gender, social origin, and social capital on educational expectations. The Journal of Higher Education, 82(1), 1-32.

Publisher's Note Springer Nature remains neutral with regard to jurisdictional claims in published maps and institutional affiliations. 